\title{
CLINICAL OUTCOMES AFTER A MORE CONSERVATIVE MANAGEMENT OF PATENT DUCTUS ARTERIOSUS IN PRETERM INFANTS
}

\author{
E. García1, A. Riverola1, V. Aldecoa-Bilbao', C. Borràs-Novell'1, M. Domingo², \\ M. Iriondo ${ }^{1}$ \\ 'BCNatal - Centre de Medicina Maternofetal i Neonatologia de Barcelona. Hospital Sant Joan de Déu. \\ Hospital Clínic. ${ }^{2 H o s p i t a l ~ U n i v e r s i t a r i ~ P a r c ~ T a u l i ́ . ~ B a r c e l o n a, ~ S p a i n . ~}$
}

\section{Introduction and aims}

Management of patent ductus arteriosus (PDA) is still controversial in extremely low birth weight infants. We aim to describe the impact of a more conservative approach in medical and surgical treatment rates and in the outcomes before discharge specially in preterm less than 26 weeks of gestation.

\section{Methods}

Review of clinical charts of preterm infants $\leq 30$ weeks with a PDA diagnosis admitted in two NICUs between 2009 and 2016. In 2011 we changed our PDA management:

- Period 1 (P1), before 2011: medical treatment was administered in cases of PDA according to the VON definition and surgical ligation was performed after failure of pharmacological treatment and need of respiratory support.

- Period 2 (P2): medical treatment was administered if the patient had clinical signs of PDA and surgical ligation was performed after failure of pharmacological treatment and cardiopulmonary compromise.

We compared medical treatment, surgical closure, mortality and survival-without-morbidity.

\section{Results}

We included 188 patients (average $27 \pm 2$ weeks and $973 \pm 272$ grams birth weight); 63 patients in $\mathrm{P} 1$ and 125 in P2. Both groups showed similar clinical characteristics. Significant lower rates of medical therapy $(85.7 \%$ vs $56.0 \%, p<0.001)$ and surgical closure $(34.5 \%$ vs $16.1 \%, p<0.001)$ were observed in P2. No differences were found in main outcomes, mortality or survival-without-morbidity. Patients born at 23-26 weeks of gestational age also received less medical and surgical treatment in P2 although neither was statistically significant. Significant differences both in the incidence of CLD $(50 \%$ vs $19.6 \%)$ and survival-without-morbidity (20\% vs $45.6 \%$ ) were found, although significance was not reached when adjusting for intubation in the delivery room.

\begin{tabular}{rccc}
\multicolumn{4}{c}{ PDA treatment and duration of its } \\
administration. Days of PDA and PDA at \\
discharge \\
\hline Period 1 $(\mathrm{n}=63)$ & Period 2 (n=125) & p-value \\
\hline Ductus size $(\mathrm{mm})$ & $2.6(0.9)$ & $2.6(0.9)$ & 0.629 \\
Ibuprofen administration & $54(85.7)$ & $70(56.0)$ & $<\mathbf{0 . 0 0 1}$ \\
Time medical treatment ${ }^{1}$ & $3[2-4]$ & $6[4-7]$ & $<0.001$ \\
Surgical closure & $20(34.5)$ & $18(16.1)$ & $\mathbf{0 . 0 0 6}$ \\
Time surgical closure ${ }^{2}$ & $24.5[17-30]$ & $27[18-35]$ & 0.766 \\
Days of PDA & $9[6-23]$ & $20[12-61]$ & $\mathbf{0 . 0 1 9}$ \\
PDA at discharge & $0(0)$ & $26(24.5)$ & $<\mathbf{0 . 0 0 1}$ \\
\hline
\end{tabular}

Values are $\mathrm{n}(\%)$, mean (standard deviation) or median [p25-p75]

${ }^{1}$ Days of live at the time that medical treatment was started

${ }^{2}$ Days of live at the time that surgical closure was performed

PDA treatment and main outcomes in each period according to gestational age

\begin{tabular}{|c|c|c|c|c|c|c|}
\hline & \multicolumn{3}{|c|}{$23-26 w(n=82)$} & \multicolumn{3}{|c|}{$27-30 w(n=106)$} \\
\hline & $\begin{array}{c}P 1 \\
(n=25)\end{array}$ & $\begin{array}{c}P 2 \\
(n=57)\end{array}$ & $\mathrm{p}$-value & $\begin{array}{c}P 1 \\
(n=38)\end{array}$ & $\begin{array}{c}P 2 \\
(n=68)\end{array}$ & $\begin{array}{c}\mathrm{p}- \\
\text { value }\end{array}$ \\
\hline Ibuprofen administration & $22(88.0)$ & $38(66.7)$ & 0.045 & $32(84.2)$ & $32(47.1)$ & $<0.001$ \\
\hline Surgical closure & $7(35)$ & $12(24.5)$ & 0.375 & $13(34.2)$ & $6(9.5)$ & 0.002 \\
\hline PDA at discharge & $0(0)$ & $9(19.6)$ & 0.056 & $0(0)$ & $17(28.3)$ & 0.001 \\
\hline Chronic Lung Disease & $8(50)$ & $9(19.6)$ & $0.019^{\star}$ & $7(19.4)$ & $8(13.1)$ & 0.405 \\
\hline $\begin{array}{r}\text { Severe Retinopathy of } \\
\text { Prematurity }\end{array}$ & $3(18.8)$ & $10(20.8)$ & 0.858 & $1(2.7)$ & $3(4.8)$ & 0.602 \\
\hline Necrotizing Enterocolitis & $5(23.8)$ & $7(13.5)$ & 0.280 & $4(10.8)$ & $1(1.6)$ & 0.039 \\
\hline $\begin{array}{r}\text { Severe Intraventricular } \\
\text { Hemorrhage }\end{array}$ & $11(44)$ & $14(24.6)$ & 0.078 & $5(13.2)$ & $9(13.2)$ & 0.991 \\
\hline Mortality & $9(36)$ & $11(19.3)$ & 0.105 & $2(5.3)$ & $8(11.8)$ & 0.272 \\
\hline Survival without morbidity & $5(20)$ & $26(45.6)$ & $0.028^{\star}$ & $26(68.4)$ & $45(66.2)$ & 0.814 \\
\hline
\end{tabular}

\section{Conclusions}

A conservative approach in preterm infants with PDA can avoid medical and surgical treatments and its side effects, without a significant impact in survival-without-morbidity. However, two thirds of preterm infants born under 26 weeks are still treated for PDA. 